\title{
Towards a Dialogic Understanding of the Relationship between Teaching Thinking and
}

\section{CSCL}

(Pre-print draft of article in press for the first issue of the International Journal of Computer Supported Collaborative Learning published by Springer due out in Spring 2006)

\author{
Rupert Wegerif \\ School of Education \\ University of Southampton \\ Highfield, Southampton, SO17 1BJ UK \\ $\underline{\text { R.B.Wegerif@soton.ac.uk }}$
}

\begin{abstract}
.
How to teach flexible thinking and learning skills, particularly creativity and the skill of learning to learn, is a key concern for Computer Supported Collaborative Learning (CSCL) in the context of the emerging Networked Society. The currently dominant paradigms for supporting pedagogical design within CSCL, including socio-cultural theory, are limited in the support that they can offer to the project of teaching general thinking skills. This paper uses critical literature review, conceptual analysis and evidence from cases studies to argue for the value of a dialogic interpretative framework that links the goal of teaching thinking with the method of CSCL. The evidence reviewed suggests that dialogue is itself the primary thinking skill upon which all others are derivative. It is argued from this that dialogic theory offers a possible solution to the problem of how to conceptualise general thinking skills for CSCL: this is that teaching dialogue as an end in itself promotes the learning of general skills, especially the skills of
\end{abstract}


creativity and learning to learn. Some of the implications of the proposed framework for pedagogical design are brought out through cases studies illustrating the use of CSCL to broaden and deepen dialogic spaces of reflection.

Keywords: Creativity; Dialogic; Learning to learn; Theory; Thinking skills.

\section{Introduction}

Within the Computer Supported Collaborative Learning (CSCL) research community there is a considerable interest in teaching general thinking and learning skills. Often this interest is explicitly linked to the claim that new skills are needed as a result of a historical shift in work and life practices (e.g Bereiter, 2002: Andriessen, et al, 2003). Castells surveys the many developments linked to the advent of electronic networks and concludes that they amount to the emergence of a new form of global social organization which he refers to as the 'Networked Society'. He concludes that this historical transition 'calls into question the entire education system developed during the industrial era' and demands that we develop a new pedagogy based around the idea of learning to learn (Castells, 2001, p 278). In this paper I argue that, although CSCL is the obvious pedagogic medium for the Networked Society some of the underlying assumptions behind CSCL pedagogies are still very much a product of the industrial age and need to be challenged. Dialogic, I argue, offers a particularly useful framework for education in suggesting the direction of dialogue as an end in itself, that is the direction of becoming more able to dwell in the contradictory, multiple and creative space of dialogue. CSCL is particularly suited to the induction of students into dialogue as an end in itself and, through this, to promote the skills of creativity and of learning to learn. 
In the next three sections I offer a brief account of the implications of dialogic, contrasting this with currently dominant paradigms in CSCL, and I outline what is meant by the pedagogic aim of teaching thinking and how this relates to the use of technology. I then advance the main argument of the paper through four case-studies.

\section{Unpacking dialogic}

The standard short definition of dialogic is that the meaning of an utterance is given by its location within a dialogue. It follows from this that to understand any utterance we have to look at the past utterances that it is responding to and the future utterances that it anticipates. Versions of this definition are widely repeated wherever the term dialogic is used in a technical sense and seem to be accepted by researchers from a range of traditions. However this simple claim has radical implications. Wertsch brings out the relationship between dialogic and a critique of identity thinking, when he writes, in definition of dialogicality: 'when a speaker produces an utterance at least two voices can be heard simultaneously' (Wertsch, 1991, p13). Bakhtin uses the term 'inter-animation' or 'inter-illumination' to indicate that the meaning of an utterance is not reducible to the intentions of the speaker or to the response of the addressee but emerges between these two (Holquist, 1981, p 429-430). The way in which each generation of scholars re-visit and re-interpret textual fragments from ancient Greece is used by Bakhtin to illustrate his claim that there can be no final or fixed interpretation of an utterance (Bakhin, 1986, p5 and 170). 
Wertsch combines Vygotsky's account of cognition as mediated by tools with Bakhtin's account of thinking mediated by 'social voices' (Wertsch, 1991: 1998). However Vygotsky draws his model of mediation from Marx's account of the use of tools as mediated physical force acting on objects in the world (Marx, Capital, p199, quoted by Vygotsky, 1978, p54). As Bakhtin points out, relationships between things are very different from relationships between voices (Bakhtin, 1986, p 138 and 162). For each participant in a dialogue the voice of the other is an outside perspective that includes them within it. The boundary between subjects is not therefore a demarcation line, or an external link between self and other, or a tool of any kind, but an inclusive 'space' of dialogue within which self and other mutually construct and re-construct each other. Any sign taken to be a mediation between self and other, a word or a facial expression, must pre-suppose the prior opening of a space of dialogue (an opening of a difference between voices) within which such a sign can be taken to mean something.

The principle that the meanings of things and signs are not stable or fixed but arise only in the context of a difference between perspectives connects dialogic to the theme of underlying difference best known through the work of Derrida, particularly his seminal essay, 'La différance'. In this essay Derrida argues that meaning is always a product of a prior invisible act of differentiating that includes even the differing of space and the deferring of time (Derrida, 1968) Derrida acknowledges that he is drawing out some of the implications in Heidegger's account of meaning as arising out of 'ontological difference', by which Heidegger means the difference between Being and beings (Heidegger, 1969). One simple way to understand Heideggers' distinction between beings and Being is through MerleauPonty's more visual account of the difference between figure and ground, the idea that all bounded 'things' or 'objects' or 'signs' or 'meanings' stand-out from and are defined against an implicit background. For Merleau-Ponty, perhaps interpreting Heidegger, the source of meaning is to be found not in the figures or in their backgrounds but in the difference between 
the two because it is the boundary around a figure that makes it exist as a thinkable thing. He goes further and writes that figure and ground, the ultimate unit of meaning, are in a relationship of mutual envelopment and reversibility which he calls a 'chiasm'. MerleauPonty applies this analysis of perceptual meaning to how meaning arises in dialogues in which voices mutually envelop each other around an invisible gap or hinge which, he writes, is the source of creative thought (Merleau-Ponty, 1964, p 194, 201: 1968, p 148, 153).

Derrida uses Mallarmé's account of his own poetry to draw attention away from the foreground signs, the black marks made by a pen, and towards the infinite potential for meaning of the white page beneath the signs (Derrida, 1972, pp 308-309). This illustrates the general claim shared by philosophical perspectives which assume ontological difference rather than identity, that creativity (in the form of 'imaginative analogy', Carter, 2002) is not a 'construction' that needs to be explained but a baseline. What needs to be explained is the loss of creativity in reified metaphors. Derrida's account of the practice of 'deconstruction' can therefore be understood as a pedagogic practice that restores creativity through questioning metaphors back to their origin in the 'white page' which represents an infinite potential for meaning or 'polysemicity'. In a similar way Bakthin emphasizes the intrinsic polyvocality and heteroglossia of the dialogic opening, and the natural creativity and fecundity of relations between living words (Bakhtin, 1981, pp 292-294).

Dialogic and the paradigms of CSCL

Tim Koschmann offers a history of paradigms in research on information technology and associates CSCL with the socio-cultural research paradigm which is also often referred to as 'neo-Vygotskian' (Koschmann, 1996). In later writing he includes 'dialogic' as one of the paradigms of CSCL but he does so through quoting Wertsch who, as described above, has been responsible for appropriating Bakhtin's dialogic to Vygotsky's more dialectically based 
social-historical framework (Koschmann, 2001). Although Wertsch's synthesis of Vygotsky and Bakthin is interesting and has been fruitful, it is also misleading. The concept of dialogic was developed by Bakthin to be an explicit contrast to dialectic (e.g. Bakhtin, 1986, p 162). Dialectic is a dynamic form of logic leading all apparent differences to be subsumed into identity in the form of a more complexly integrated synthesis, it is not dialogic since dialogic refers to the inter-animation of real voices where there can be no 'overcoming' or 'synthesis'. For dialectic, difference is conceptualized as a contradiction stimulating the creative construction of some sort of synthetic representation, whereas for dialogic, meaning itself only arises when different perspectives are brought together in a way that allows them to 'interanimate' or 'inter-illuminate' each other (Holquist, 1981). The dialectic assumption that new understanding is a synthetic construction stimulated by a contradiction is also found in other theories that Koschmann associates with CSCL such as neo-Piagetian socio-cognitive conflict theory and Engestrom's version of Cultural Historical Activity Theory (Koschmann, 2001). Bakhtin argues that understanding is a direct insight that occurs in the context of the tension between different voices in a dialogue. For him the idea that we need to synthesise a shared single 'text' out of different perspectives actually threatens the death of meaning because it threatens to close up the 'infinite depth' of 'contextual meaning' that opens up beneath dialogues across difference (Bakthin, $1986 \mathrm{p}$ 162). Tim Koschmann is right to argue that dialogic offers a new and important paradigm for CSCL (Koschmann, 1999) but to make this the case Dialogic needs to be distinguished clearly from the competing voices of sociocultural theory and social-constructivism.

Teaching thinking, dialogue and technology

'Thinking skills' and related terms such as 'learning to learn', are used to indicate a desire to teach processes of thinking and learning that can be applied in a wide range of real-life 
contexts. The list of thinking skills in the English National Curriculum is similar to many such lists in including information-processing, reasoning, enquiry, creative thinking and evaluation. While some approaches to teaching thinking treat such skills as separate, other approaches treat them all as aspects of high quality thinking or 'higher order thinking'. In practice thinking skills programmes do not all focus on the narrowly cognitive but promote a variety of apparently quite different kinds of things including, strategies, habits, attitudes, emotions, motivations, aspects of character or self-identity and also engagement in dialogue and in a community of enquiry. These 'thinking skills' are not united by any single psychological theory. It is probable that the only unity they have is that they are all those sorts of things that practitioners believe can and should be taught or encouraged in order to improve the perceived quality and/or the effectiveness of their students' thinking. (Wegerif, 2003).

Lauren Resnick chaired a major US government inquiry into the nature and value of teaching thinking skills which came up with a widely quoted account of the nature of 'Higher-Order Thinking Skills' (Resnick, 1987). According to Lauren Resnick, higher-order thinking:

- is non algorithmic. That is, the path of action is not fully specified in advance.

- tends to be complex. The total path is not "visible" (mentally speaking) from any single vantage point.

- often yields multiple solutions, each with costs and benefits, rather that unique solutions.

- involves nuanced judgement and interpretation.

- involves the application of multiple criteria, which sometimes conflict with one another.

- often involves uncertainty. Not everything that bears on the task at hand is known. 
- involves self-regulation of the thinking process. We do not recognise higher-order thinking in an individual when someone else "calls the plays" at every step.

- involves imposing meaning, finding structure in apparent disorder.

- is effortful. There is considerable mental work involved in the kinds of elaborations and judgements required. (Resnick, 1987)

Resnick describes these attributes as if they were the characteristics of a certain type of 'thought' - higher order thought - but they are almost all (self-regulation being a possible exception) aspects of situated dialogues (where dialogue is assumed to be not just conversation but also shared enquiry, following Bakhtin, 1986, p 114 and p 168). The term 'higher order thinking skills' is normally used to contrast these with 'lower order thinking skills' described in Bloom's taxonomy as skills such as 'comprehension' and 'memorisation' (Bloom, 1956). Some educationalists think that the lower order skills should be taught first as a basis for the higher skills. This is not the point of view taken by Mathew Lipman, founder of the successful Philosophy for Children method of teaching thinking. He points out that, just because wholes are capable of being analysed into parts, it does not follow that the assemblage of parts must precede the construction of wholes. His philosophy method inducts children directly into that kind of dialogue which he considers to be the highest possible form of thinking in the belief that all the necessary individual skills will follow from this (Lipman, 2003).

CSCL implies a focus on social rather than individual learning. As Koschmann and Jerry Stahl bring out, this focus on the social distinguishes CSCL from both the behaviourist and the cognitivist/constructivist traditions that underlie previous approaches to the relationship between ICT and teaching thinking (Koschmann, 1996: Stahl, in press). Many writers in the CSCL tradition refer to the ideas of educational psychologist Vygotsky to provide intellectual 
authority for a turn towards the social dimension of learning. Vygotsky is often presented as providing a psychological version of Marx's claim that individual thought is a product of the social and historical context (e.g. Edwards, 1996, p43). In particular Vygotsky claims that language is a tool-system that mediates thought and the development of thought. If language can play the role of a cognitive technology mediating and supporting thought, then this implies that so too can other technologies of communication. The approach of locating thinking skills in types of dialogue, argumentation for example, supported by technology, could be seen, from this perspective, as an attempt to include a better understanding of how general thinking skills can be taught (Ravenscroft and Pilkington, 2000; Andreissen et al, 2002). However while some kinds of thinking, formal reasoning for example, can be described in terms of the application of tools the use of tools does not adequately address the non-algorithmic and unpredictable nature of creative 'higher order' thought described by Resnick.

Dialogic has emerged as a voice in educational research within the umbrella of the sociocultural tradition, however, as shown in the previous section of this paper, unpacking the full implications of dialogic lead to a challenge to key assumptions in the socio-cultural tradition and therefore require that dialogic be treated as a separate paradigm in its own right. The ontological interpretation of dialogic that I have outlined above suggests that dialogues are not only situated, they are also, in a sense, universal. This is because any account of the situation of an empirical dialogue in terms of its horizon of history or culture, for example, must be an interpretation within a dialogue. The opening of dialogue therefore precedes situation and can be conceptualized as an opening of infinite possibility or potentiality. This is not, of course, a version of the overarching universality of abstract cognitive structures but more an underlying content free universality represented metaphorically by Mallarme's metaphor of the white page as an implicit whole of potential meaning out of which actual meanings are all carved. 
This dialogic paradigm suggests a new approach to teaching general thinking and learning skills in which dialogue is itself understood as the primary thinking skill upon which other skills are derivative. A dialogic vision for teaching thinking is developed further in the first case study below and its implications for the design of CSCL, are then exemplified in the following three short case studies.

Case study 1: Dialogue as a direction for education

Over a decade ago a research study found that the educational quality of collaborative learning around computers in primary classrooms in the UK was disappointing. In response to this finding an intervention was devised promoting 'Exploratory Talk' for use around computers. Exploratory Talk is a type of talk in which questions are asked, alternatives explored and reasons given. A method was devised to assess the effectiveness of the way groups were talking together using Raven's Standard Progressive Matrices (Wegerif, 1996). These tests are designed to assess individual 'non-verbal' reasoning ability in a 'culture-free' manner, and consist of a grid of abstract designs (see Figure 1). RSPM test scores correlate well with later academic achievement and are considered by those in the field of psycho-metrics to be the single best indicator of ' $\mathrm{g}$ ' or general intelligence (Raven at al, 1995). However the method used to assess group talk undermined the individualist tradition of assessing general reasoning skill through the simple expedient of giving the test to groups of three students, each group having only one answer sheet and only one pencil between them with which to fill in the answer sheet. Video recordings of groups working together around these tests provided qualitative data on group thinking processes; interpretation of this data was then compared to quantitative measures of success at solving the problems in the test. Comparable Raven's reasoning tests were also given to the same students working as individuals in order to explore the relationship between group thinking and individual thinking. This method was used as a 
pre and post-test (with controls) to assess the effectiveness of the intervention programme in improving the quality of talk at computers in three studies in the UK and in two in Mexico. The headline findings from these studies were that:

a) the intervention programme coaching exploratory talk statistically improved the ability of groups to solve reasoning tests;

b) this increase in scores correlated with qualitative changes in the talk of groups, particularly an increase in indicators of explicit reasoning such as logical connectors;

c) individual scores on comparable reasoning tests also improved significantly as a result of engagement in group reasoning (Wegerif, Linares et al 2005).

In one project this assessment method was implemented as part of a larger study designed to improve the quality of talking, thinking and learning in CSCL activities in mathematics and science over one year at upper primary level (with students aged 9 and 10 years old). Similar changes in the quality of talk at the computer were observed within these curriculum activities and these were similarly correlated with improved scores on standard tests of content knowledge over a year in relation to a control group (Wegerif, 2004).

These headlines were reported within a neo-Vygotskian interpretative framework as evidence for the claims that reasoning can be embodied in a type of interaction, that language can be used as a 'tool for thinking' supporting to the 'shared construction of knowledge' and that individual reasoning can be improved through the 'internalization' of improved group reasoning.

These neo-Vygotskian claims were supported with detailed analyses focusing on the change in talk around problems that groups failed to solve in the pre-test and succeeded in solving in the post-test: in other words the great strength of this experimental design is that it allowed for a 
direct comparison between successful group thinking and unsuccessful group thinking. These detailed analyses, conducted both in the UK and in Mexico, did support the Vygotskian claim that language was being used as a tool for thinking, but two other aspects also emerged that implied the need for a more genuinely dialogic interpretative framework. The first of these is that change in language use was accompanied by a shift in intersubjective orientation.

Unsuccessful group talk failed in mainly two ways, through each individual identifying with their own self-image in the dialogue and so trying to impose what they saw as their position on the others or through individuals identifying with a sense of group identity and uncritically agreeing with each other in order to avoid any disruption to what was felt as group solidarity. In successful group talk the most obvious difference was that individuals were able to change their minds, to question their own positions and to ask for help when they did not know the answer. This shift in attitude can be seen in all the published extracts of transcripts from this method. An example is given below in Transcript Extract 1.

Figure 1: Ravens Problem $\mathrm{B}^{1}$

\footnotetext{
${ }^{1}$ This is a parallel problem to Raven's B12 prepared for publication with the permission of Dr John Raven who holds the copyright for Raven's Reasoning Tests.
} 
The full transcript of one group of nine year old children (whom we called Tara, Perry and Keira) working on a version of the problem shown in Figure one, in a pre-test and again in a post-test, is published in Wegerif and Dawes, 2004, pages 37 to 39 so only three short extracts are reproduced here.

Transcript extract 1: Pre-test initiation and challenge

Tara: $\quad$ Square and diamond, it's 2.

Perry: $\quad$ No it's not.

Tara: $\quad$ It is 2 .

Perry: No it's not.

Tara: $\quad$ It is. 
In the pre-test Tara, a girl, initiates with a suggestion, Perry, a boy, rejects it and they move into a dispute. This disputatious approach continues and eventually Perry imposes his own solution, number 6 , against the opposition of two girls, Tara and Keira, by grabbing the pencil and writing down his answer in the space provided.

Transcript extract 2: post-test initiation and challenge

Tara: That has got to be a diamond, a square with a diamond with a circle in that one, number 6 , do you agree?

Perry: No, what do you mean?

Tara: $\quad$ OK, no it's got to be square.

In the post-test, three months later, the same group respond to the same problem quite differently. When Tara suggests number six she does so with a question asking if the others agree, Perry then asks her politely to clarify her reasons and, in the act of reflecting on her claim, Tara changes her mind. The talk continues for some time exploring different alternatives. The video also shows long pauses with the group all leaning forwards towards the problem sheet with concentrated expressions. Eventually Tara sees the correct answer and tries to communicate this to the others.

Transcript extract 3: Post-test, sharing the solution

Tara: Look, that's got a triangle, that's got a square. Look. that's got a square with a diamond with a circle in, that's got a square with a diamond in and that's got a square with a circle in so that's got to be a square.

Perry: I don't understand this at all.

Tara: Because, look, on that they've taken the circle out yes? So on that you are going to take the circle out because they have taken the circle out of that one. 
Perry: On this they have taken the circle out and on this they have taken the diamond out and on this they have put them both in, so it should be a blank square because look it goes circle square.

Commentary based on the video evidence: After Tara tries to explain her vision, Perry admits that he does not understand her in a way that invites her help. Tara then tries again using the phrase 'taking the circle out'. Perry suddenly seems to see the answer. His eyes light up and he shows signs of pleasure and excitement. He then repeats Tara's words 'taking the circle out' with energy and animation to express his new understanding.

Discussion of case study

The shift in the way this group worked together was fairly typical pre to post changes found in the data in both the UK studies and the Mexican studies. Although this was an off-computer paper exercise it was a part of a larger project to improve the collaborative learning around computers and the characteristics of the talk of successful groups were also found in successful groups working at CSCL activities within curriculum areas making this study of group cognition relevant to the concerns of CSCL (Wegerif, 2004. see also Stahl, in press). It is not wrong to claim that language is being used here as a tool to think with and that this helps the children to construct a solution together. However this neo-Vygotskian perspective is only part of the story. The key factor in the success of the post-test talk is that both Perry and Tara became able to listen to each other, change their minds and ask for advice. This implies a shift in their centre of identification from an initial identification with an embodied self-image, which needed to be asserted and defended, to an identification with the shared space of dialogue from which self-positions could all be questioned and changed. The other thing that is interesting, from a dialogic perspective, is that 'language as a tool' does not directly solve the problem. This is solved in an act of insight, a way of seeing the puzzle, 
which Tara then struggles to communicate to the others in words. Perry does not understand her at first then understands her, not through repeating her words but by using them as a stimulus to re-orient himself to the puzzle and to see it in a new way, it is only then that he understands and repeats her verbal formula. The ground rules of Exploratory Talk that were taught in the intervention do help the children to solve the problem, this is shown by the statistics, but they only help indirectly. An interpretation from the dialogic framework outlined above is that ground rules, such as listening with respect and asking open questions, help to open and maintain a space of shared reflection within which there occurs a creative emergence of multiple ways of seeing the problem one of which is then taken up and developed as the solution.

The findings of this case study suggest three main conclusions: that it is possible to suspend identification with self-mage or group image and to identify to a greater or lesser extent with the space of dialogue; that moving towards an ability to feel at home in dialogue in this way is a direction that can be promoted through education and that the space of dialogue is a space of possibility such that an increased identification with the space of dialogue leads to increased capacity for creative thinking and problem solving.

The claim that education can promote a direction of increased identification with the space of dialogue is a contradictory claim if one considers that the space of dialogue is defined above through its non-identity, being precisely that 'no-mans land' where multiple voices co-exist simultaneously. However, if this is an oxymoron, it is a useful oxymoron in pointing to the development of a kind of identity that is more open to other perspectives, and more at home in multiplicity. While complete identification with the infinite meaning potential that underlies the opening of a dialogue would imply a loss of self-identity the reality of becoming a creative 
thinker involves a dynamic combination of losing oneself and finding oneself again which can perhaps be summed up in the idea of developing a more dialogic identity.

This case study also illustrates and exemplifies the claim that a dialogic perspective builds upon a neo-Vygotskian account of thinking as tool use, but locates this within a larger perspective from which it is interpreted differently. In this example we see the phrase 'taking the circle out' being co-constructed as a useful tool for consolidating and sharing an insight. However it is only in the context of dialogic relationships in which things can be seen from multiple perspectives at once, that sign-tools such as this have any meaning. Not only do tools of this kind pre-suppose a dialogic relationship, they also remain within it, so for instance, the phrase 'taking the circle out' has to be re-animated and lived by Perry as a way of re-seeing the Raven's puzzle from the perspective first achieved by Tara. Whereas what is constructed is always a representation of some kind, understanding is always a lived event. When Perry later, did better on individual Raven's tests than he had before his engagement in group thinking, a dialogic perspective would suggest that he had not 'internalized' explicit tools such as 'taking the circle out' but that he had internalized, or appropriated, the creative dialogic space within which such tools emerge as and when they are needed to solve a problem: this is the space of possibilities opened up by dialogue enabling a problem to be seen from multiple perspectives at once.

Designing for expanding dialogue: The forum

In the CSCL strand of the programme of projects described above, a variety of software activities were developed or selected to be used in combination with the promotion of exploratory talk. One design which proved effective in both citizenship and science was that of the forum of competing voices. In the area of education for citizenship a branching narrative was developed in which the heroine, Kate, has to make decisions about how to 
respond when her friend, Robert, admits that he stole some chocolates. This story ends with a forum in which all the characters in the story present their account of whether or not Kate 'did the right thing' and the children have to use these voices as a resource for making their own decision. When used after preparation in the ground rules of exploratory talk, this forum worked well in stimulating wide ranging debate about the issue of stealing. In these debates the primary age children were happy to challenge the opinions of adults in the story, such as the shopkeeper, the policeman and the headteacher, in order to articulate their own perspective. The strength of this design is that it inducts learners into dialogue in a specific domain in a way that is focused but not bounded. There were many examples of both what Bakhtin would call intertextuality and also ventriloquation as the learners called upon their experience and practiced voices drawn from a range of contexts.

In education for creativity there is a stress on the importance of teaching everything not as fact but as 'possibility' (e.g. Craft, 2005). One way of doing this is for teachers never to claim something 'is' the case but always that it 'might be' so, thereby suggesting to the students that it might also be otherwise and shifting the focus from the idea of true knowledge to the process of dialogue and enquiry. The forum design described above is particularly suited to the interactive potential of computers. It does not need to be limited to articificially constructed debates of the kind described, but, in combination with use of the World Wide Web, it can be used to induct learners into real debates between different perspectives on any and every issue. Web-quests, for example, can be structured not as a 'finding out the truth' type of exercise but more as 'an exploring the space of debate' type of exercise.

Designing for deepening dialogue: Bubble Dialogue

Talk in face-to-face dialogues exists only momentarily and only for those immediately present. Technologies that support drawing and writing can thus be thought of as a way of 
deepening dialogues, by turning transitory talk and thoughts into external objects that are available to learners for discussion and shared reflection (Ong, 1982). Computer documents can offer a kind of half-way stage between the evanescence of talk and the permanence of written texts. This is part of what Harry McMahon, one of the originators of Bubble Dialogue software, refers to as 'slow-throwness' (McMahon and O'Neill, 1993). By this term he refers to the way that Bubble Dialogue can externalise the thoughts and feelings of the participants and also support reflection and the possibility of returning and retrospectively changing dialogues. An example of such dialogue is provided in the Bubble Dialogue reproduced in Figure 2 and extract 4 below. This was created by Charlene and Rory, both aged 10 years, and both excluded from their previous schools because of behavioral difficulties. They are discussing a Bubble Dialogue scenario about a personal conflict involving characters called Joe and Greg. In the story Greg was using his new skateboard in the playground when Joe, a bigger boy, grabbed it from him.

In the first exchanges both characters 'square up' for a physical fight. However, the next set of think bubbles that Charlene and Rory produced (see Transcript Extract 4) indicate that while both parties are prepared to fight over the skateboard 'asking nicely' or apologizing would diffuse the situation.

Figure 2: Bubble Dialogue 
Transcript extract 3 (Bubble Dialogue) : I'm not scared

(Joe thinks: he just have to ask nicely)

Joe says: I'll kick your head in you fat brat head

Greg says: yeah come on then, I'm not scared of you if im a big fat brat head what does that make you, you peebrain

(Greg thinks: im not scared of him all hes got to do is give me my skateboard back and apologise to me, if he doesn't im going to break his big fat ugly bogied up nose)

Charlene and Rory's story goes on to have Joe give Greg the skateboard back. When Greg insists on an apology, Joe denies having taken the board and says that Greg should say sorry for threatening to punch his lights out when he was only playing. Eventually they both manage to apologize in a guarded way and agree to be friends. 
Transcript extract 3 shows that, as well as their obvious enjoyment in the use of insulting language, they were also able to explore the distinction between what their proxy characters were saying and what they were thinking. This implies a reflective exploration of their own motives. Although the characters were acting tough they did not actually want to fight and through using the Bubble Dialogue program they rehearsed a way to talk themselves out of the fight that had at first seemed to be inevitable. The features of Bubble Dialogue allowed them to externalize their own image and reflect on it, to consider the difference between what they say and what they really think in order to explore the consequences of their speech in a context where they can go back and change what they say until they get the outcome that they want. All these features deepen the space of reflection involved in a dialogue in a way that increases the degrees of creative freedom because it is only through becoming more aware of who one is through a dialogue that one is able to change (Bohm, 1996).

Scaffolded induction into online dialogue: InterLoc

Synchronous messaging or has become popular as a means of communication and seems to produce more motivation as a medium for CSCL at a distance than asynchronous communication. However, as a medium, synchronous messaging does not support shared inquiry as well as it supports social conversation because messages disappear too fast for deep reflection. InterLoc is a software tool designed to turn synchronous 'chat' into learning dialogue through two means: firstly providing an interface which allows participants to return to previous messages and contribute to developing threads of argument and secondly through constraining users to use a limited set of openers and preferred follow-on openers that define what the developers, Andrew Ravenscroft and Simon McAlister refer to, as a 'dialogue game' (Ravenscroft and McAlister, in press). This current language game used is called 'Critical Discussion and Reasoning' and includes questions such as 'Why do you think that?' and 
challenges such as 'I disagree because..'. Other language games focusing more on creativity and on empathy have been designed by the research team and are also being tested (Wegerif, Ravenscroft and McAlister, 2005). Trials of this system suggest that it does deepen the quality of dialogue and allow for the broader exploration of issues. It might be thought that the prescribed openers would frustrate users, and the reaction is often one of frustration initially, but most users get highly engaged in debates and report that they like the system partly because it provides a kind of alibi that they can hide behind. Putting forward ideas and questioning those of others can be socially difficult, especially when those others are unknown and located at a distance. Shared acceptance of the rules of the language game built into the software allows users to challenge each other and explore issues more freely than they would do otherwise. The debates that occur using this system are not reducible to abstract structures of explicit reasoning, or to simple notions of constructing shared knowledge. They consist more in a divergent exploration of a field of potential perspectives on a topic. Through using this tool participants report that they are stimulated to think more deeply (Wegerif, Ravenscroft and McAlister, 2005).

\section{Conclusions}

The teaching and learning of general thinking skills, especially creativity and learning to learn, is hard to understand through a neo-Vygotskian perspective which focuses on the use of tools for the social construction of knowledge. Understanding is an event within a dialogue between perspectives and is not reducible to a constructed representation. A focus on tools and construction cannot explain creative insights and is hard to convert into a pedagogy for teaching general thinking skills since tools are always specific to tasks. Teaching thinking is much easier to understand through a dialogic perspective which focuses on the opening, deepening and broadening of reflective spaces. What is missing from the neo-Vygotskian 
account is the importance of the implicit space of possibilities opened up by dialogue which allows for creative emergence and which is the irreducible context for the interpretations of signs and representations. This dialogic interpretative framework implies the need for a pedagogy of teaching dialogic, that is the ability to sustain more than one perspective simultaneously, as an end in itself and as the primary thinking skill upon which all other thinking skills are derivative. This pedagogy can be described in terms of moving learners into the space of dialogue. Tools, including language and computer environments, can be used for opening up and maintaining dialogic spaces and for deepening and broadening dialogic spaces. In many cases the pedagogic practices that follows from this dialogic interpretative framework are already happening, this includes the promotion of communities of enquiry and dialogue skills, the use of forums of alternative voices to induct students into debate, engagement in real dialogues across cultural and geographic differences using the internet, scaffolding induction into such dialogues using synchronous and asynchronous environments, amongst others. The purpose of the dialogic framework for CSCL is therefore not necessarily suggesting new pedagogical strategies but rather in providing an interpretative framework that can be applied retrospectively to pedagogical practices that have emerged through the intuition of practitioners in a way that reveals what is of real value in these practices and so can serve as a basis for future design.

The dialogic framework proposed in this paper responds to the educational needs of our cultural and historical situation as articulated by Castells (2001, p 278). The internet is, amongst other things, an expanding cacophony of competing voices. Teaching general thinking and learning skills, in the context of the shift to a global 'Networked Society', is at least partly about teaching students how to use the internet for thinking and learning. Whilst 
being able to participate in the construction of shared knowledge is clearly an important aim of education, the dialogic perspective argued for in this paper claims that it is even more important, as both a preliminary requirement for construction and as the context of construction, that students in the networked society learn how to listen to other voices. Against the dominant metaphor of knowledge construction, this dialogic perspective argues that the emergence of creative new insights presupposes a capacity for suspending assumptions and dissolving previous constructions in order to be able to enter more deeply into the space of dialogue.

\section{REFERENCES}

Andriessen, J., Baker, M., Suthers, D. (2003). Argumentation, Computer Support, and the Educational Context of confronting cognitions. In Andriessen, J., Baker, M., Suthers, D. (Eds.), Arguing to Learn: Confronting Cognitions in Computer-Supported Collaborative Learning environments (pp. 1-25). Dordrecht: Kluwer

Bakhtin, M. (1981) The Dialogic Imagination. Austin: University of Texas Press.

Bakhtin, M. (1986) Speech Genres and Other Late Essays. Austin: University of Texas Press .

Bereiter, C. (2002). Education and mind in the knowledge age. Mahwah, NJ: Lawrence Erlbaum Associates.

Bloom, B.S. (Ed.) (1956) Taxonomy of educational objectives: The classification of educational goals: Handbook I, cognitive domain. New York ; Toronto: Longmans, Green.

Bohm, D. (1996) On Dialogue. Edited by Lee Nichol. London ; New York : Routledge.

Carter R. (2002) Language and Creativity. London: Routledge 
Castells, M. (2001) The Internet Galaxy: Reflections on the Internet, Business, and Society. New York: Oxford University Press.

Craft, A. (2005) Creativity in Schools: Tensions and Dilemmas. London: Routledge

Derrida, J (1972) La Dissémination. Paris: Seuil

Derrida, J. (1968) La Différance. In Théorie d'ensemble, Paris: Éditions de Seuil. 43 - 69.

Edwards, D. 1996. Discourse and Cognition. London: Sage.

Heidegger, M. (1969) Identity and Difference. Bilingual ed., trans. J. Stambaugh. New York: Harper and Row

Holquist, M. (1981) Glossary for Bakhtin, M. The Dialogic Imagination. (Austin, University of Texas Press).

Koschmann T. (ed) (1996) CSCL: Theory and Practice of an Emerging Paradigm, Mahwah, JJ: USA: Lawrence Erlbaum Associates,.

Koschmann, T. (2001). Revisiting the paradigms of instructional technology. In G. Kennedy, M. Keppell, C. McNaught \& T. Petrovic (Eds.), Meeting at the Crossroads. Proceedings of the 18th Annual Conference of the Australian Society for Computers in Learning in Tertiary Education. (pp. 15 - 22).

Koschmann, T. D. (1999). Toward a dialogic theory of learning: Bakhtin's contribution to understanding learning in settings of collaboration. In C. M. Hoadley and J. Roschelle (Eds.), Proceedings of the Computer Support for Collaborative Learning (CSCL) 1999 Conference (pp. 308-313). Mahwah, NJ: Lawrence Erlbaum Associates.

Lipman, M (2003) Thinking in Education (2 ${ }^{\text {nd }}$ Edition). Cambridge, UK: Cambridge University Press. 
McMahon, H and W. O’Neill. (1993) Computer-Mediated Zones of Engagement in Learning, in Tom Duffy, J. Lowyk and D. Jonassen (eds.) Designing environments for constructive learning, Berlin: Springer-Verlag.

Merleau-Ponty, M. (1964) Le Visible et L'Invisible, Paris: Gallimard.

Merleau-Ponty, M. (1968) The Visible and the Invisible, Edited by Claude Lefort, translated by Alphonso Lingis. Evanston, Il: Northwestern University Press.

Ong, W. J. (1982). Orality and Literacy: The Technologizing of the Word. London: Methuen.

Raven, J., Raven, J. C., \& Court, J. (1995). Manual for raven's progressive matrices and vocabulary scales. Section 1: General Overview. (1995 ed.). Oxford: Oxford Psychologists Press.

Ravenscroft, A. \& Pilkington, R.M. (2000). Investigation by Design: Developing Dialogue Models to Support Reasoning and Conceptual Change, International Educational Dialogue Interaction: From Analysis to Models that Support Journal of Artificial Intelligence in Education: Special Issue on Analysing Learning, 11/1, 273-298.

Ravenscroft, A., and McAlister, S. (In press) Designing Interaction as a Dialogue Game, In Interactions in Online Education, Juwah, C (Ed). Routledge

Resnick, L. (1987). Education and learning to think. Washington, DC: National Academy Press.

Stahl, G. (In press) Group Cognition: Computer Support for Building Collaborative Knowledge. Cambridge, Ma: MIT press

Vygotsky, L.S. (1978). Mind in society: The development of higher psychological processes. Cambridge, MA: Harvard University Press. 
Wegerif, R. (2004) The role of educational software as a support for teaching and learning conversations. Computers and Education. 43 (2), 179-191

Wegerif, R. and Dawes, L. (2004) Thinking and learning with ICT: raising achievement in primary classrooms. London: Routledge.

Wegerif, R., Perez Linares, J., Rojas Drummond, S., Mercer, N., Velez, M (2005) Thinking Together in the UK and Mexico: transfer of an educational innovation. Journal of Classroom Interaction. Vol 40, No 1.

Wegerif, R., Ravenscroft, A \& McAlister, S. (2005). Investigating the social dimension of induction into argumentation, EARLI Conference, Nicosia, Cyprus, 23-27 August 2005.

Wertsch, J. V. (1991). Voices of the Mind. New York: Harvester.

Wertsch, J.V. (1998) Mind as Action. New York: Oxford University Press. 